\title{
NOTES AND REVIEWS
}

\author{
ANTHROPOLOGICAL ASPECTS OF ALCOHOL TRADE IN \\ MICROSOCIETIES OF CHUKOTKA NATIONAL SETTLEMENTS
}

The process of buying and selling alcohol, when it happens on an interpersonal level in a microsociety, goes beyond a simple exchange of material values. In such trade there is always a moral (or immoral) context. Moreover, interactions on the subject of alcohol are the reflections of interethnic and political relations when representatives of different social and ethnic groups participate.

On the basis of ethnographic field materials I would like to characterise the participants in alcohol-related interactions in order to reveal the motives for their behaviour and perception of each other. My aim is to describe the communicative culture that has been established between the home-made vodka traders (home-distilled vodka producers), alcohol buyers and activists fighting for temperance.

In the title of my report ${ }^{*}$ there is a reference to the microsociety of national settlements in Chukotka. Informal economic relations take place within particular settlements; the main thing that is involved in these relations is alcohol. Outside the settlement the connections between traders and buyers do not work and the network of interactions breaks.

To mark out the participants in the alcohol trade I will present the structure of settlement microsociety in Chukotka from a very generalised perspective, based on my experience of staying in these settlements and on some statistical data.

In order to demonstrate this I have made a scheme (Figure 1) that illustrates how participants in alcohol-related interactions are allocated in the settlement microsociety of Chukotka.

1) Newcomers - 'Russians', employees of government-financed organisations, teachers, doctors, administration workers, allochthonic population: $5-10 \%$ of the economically active population (EAP).

2) Native inhabitant elite - elders, representatives of the Association of Indigenous Less-Numerous Peoples of Chukotka, educated native inhabitants: 7-15\% EAP.

3) Indigenous people with no or low income - unemployed, low-skilled workers, free hunters and fishermen, native inhabitants with a low level of education: 70-85\% EAP.

4) Reindeer breeders - reindeer-breeding nomad camp dwellers: 7-10\%.

5) Sea hunters - workers of sea animal catch artels: $4-7 \%$ EAP.

People of these conditional groups are participants in alcohol-related interactions:

1) Purchasers (85-90\% EAP). Alcoholism and drunkenness among the indigenous

* This research was carried out with the financial support of the Russian Foundation for Basic Research, within the research project titled Alcohol in the Micro-Society of Chukotka Settlement: Ethnographic Research of Ethno-Cultural, Social and Economic Interactions, project no. 15-3101272 . 


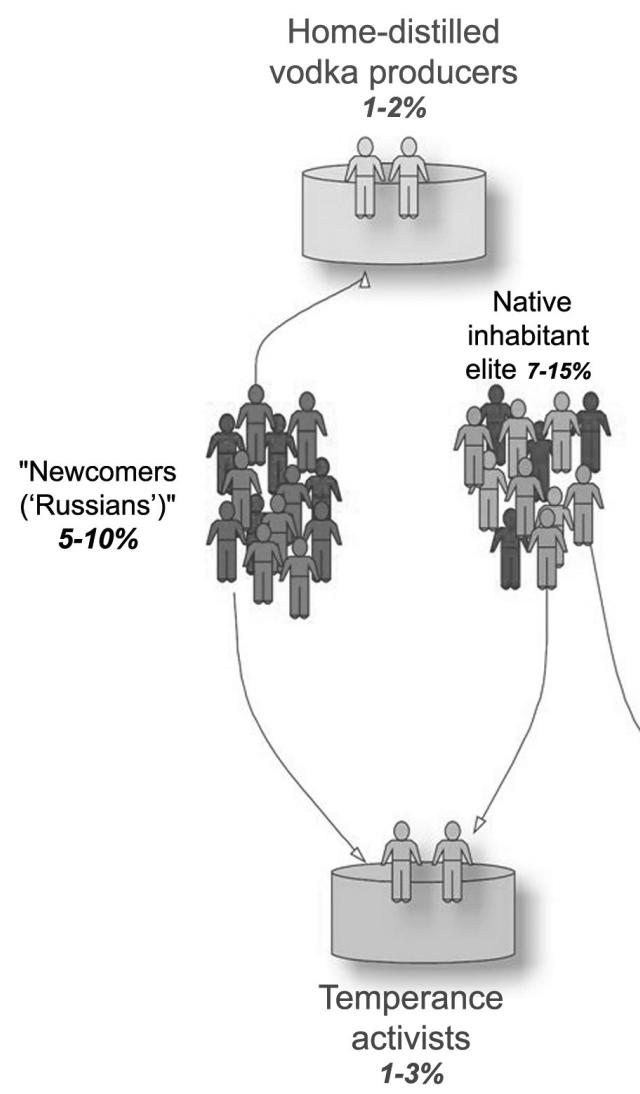

population of the Chukotka settlements are serious problems and, accordingly, the demand for alcoholic beverages remains stable. According to unofficial data from medical workers and leaders of the administration, $23-47 \%$ of the adult population in the Chukotka settlements are addicted to alcohol.

2) Home-distilled vodka producers, socalled bootleggers (1-2\% EAP). In addition to legal shops, alcohol is offered by those who produce home-made alcoholic drinks (braga and home brew). These people have a distinct position in a settlement's social structure and economy: they receive some part of the household income from selling home-made alcohol, they have a great psychological impact on buyers and, at the same time, they feel constant public pressure.

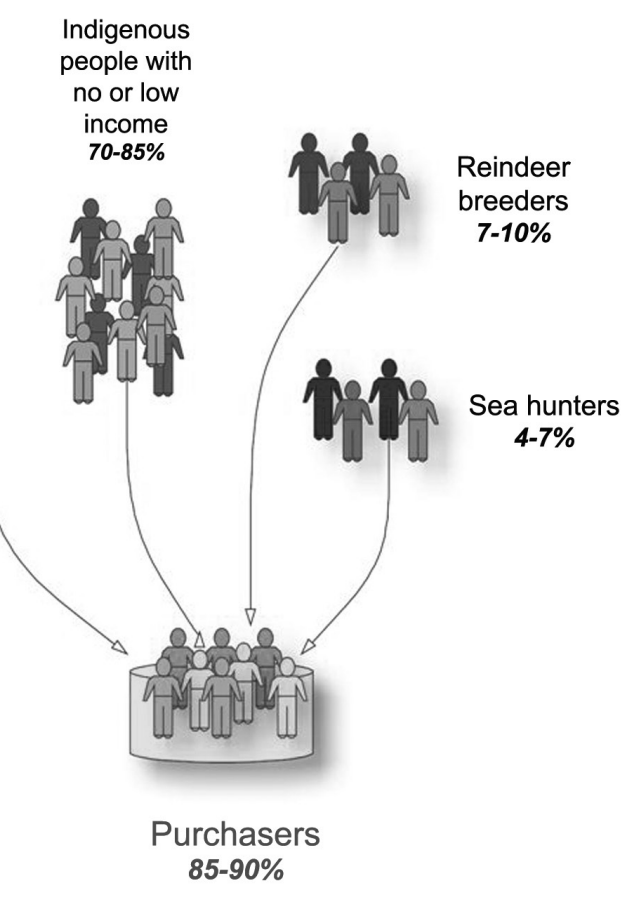

3) Temperance activists (1-3\% EAP). Measures available to fight against the illegal distillation and sale of alcohol are limited at present by the public pressure to home-distilled vodka producers. Public pressure is created by a small group of temperance activists. These people do not take part in the buying and selling process directly, although they affect the trading process, making attempts to ruin it and an make impact on the economic side of the interactions between traders and buyers.

A subdivision of trade participants on an ethnic basis is observed: most of the bootleggers are newcomers, Russians, Ukrainians and other representatives of non-indigenous peoples, while the buyers are mainly indigenous Chukotkans, such as Chukchis, 
Eskimos, and Evens. Temperance activists are mainly of mixed ethnic background.

In the everyday life of the settlements alcohol buyers, temperance activists and sellers interact continuously. The nature of these interactions depends on cultural differences, specific features of economic behaviour and accepted unspoken rules.

Informants emphasised that these are in particular 'Russians' who produce homedistilled vodka; native inhabitants, according to my informants, do not produce or sell home-distilled vodka. I can see several reasons why native inhabitants were not included in the group of traders.

1) A cognitive division of labour made by native inhabitants separating 'their labour' and 'Russian labour'. Producing home-distilled vodka, as with all activities not related to traditional economics, is the 'labour of Russians'.

2) Gender segregation of labour within the culture of native Chukotkans. Producing home-distilled vodka - as a peculiar kind of food preparation - is from the perspective of traditional culture women's labour. Male representatives of native peoples think that doing women's labour contradicts traditional gender roles.

3) Peculiarities of labour culture, which reject regulation in the labour sphere. Producing home-distilled vodka is in compliance with the technological process, presupposing a certain self-organisation and regulation of activities - all characteristics that restrict the freedom of the native inhabitant. This is why they are not interested in distilling alcohol even though it can be particularly lucrative.

Relations with the producers of home-distilled vodka, and interaction with them, is closely connected with the native inhabitants' concept of the alcohol. Native inhabitants of Chukotka connect this product with the supernatural. In speech they avoid naming alcohol directly or talk about it allegorically. Chukchis name alcohol using the word e'k'imyl, which can be translated as 'bad water'. The word has a high value in the worldview of the Chukchis, Eskimos, Yukagirs; similarly everything that is somehow connected with supernatural is not articulated in everyday life.

The producer of home-distilled vodka as the person who makes alcohol is also considered to have supernatural abilities. According to the narratives of my informants, these abilities are manifested in the ability to influence weather, bedevil people, and use magic in order to fight enemies and influence people.

At the same time the magic power of the producer of home-distilled vodka, in the worldview of native inhabitants, appears to be linked to the territory where he sells alcohol, particularly in the settlement. If a producer goes to another territory outside the borders of Chukotka, he not only loses his supernatural abilities, but various misfortunes follow him and his family leading ultimately to death. Similar ideas point to a connection between producers of home-distilled vodka and local ghosts, who allow the producers to sell the alcohol.

The behaviour of the buyers during the bargaining process depends on exchange traditions and the communicative culture of buyers. For example, reindeer breeders in most cases did not purchase alcohol directly, they prefer to use dealers. Intermediation in the trade was the traditional means Chukchis communities. Before the Soviet period the dealers - kavral'yt (literally 'turners'), usually coastal Chukchis - travelled around the nomadic reindeer-breeding camps and performed commodity exchange. They had personal connections with reindeer breeders and knew the exchange traditions.

The process of purchasing alcohol by the native inhabitants differed from case to case but can be divided into two main types. Firstly, an ambiguous formulation of the arrival purpose, embarrassment, con- 
fused expressions. The second is the reverse behaviour: a loud knock on the door or window, shouting, noise close to the home of the producer, arrival at night, aggression if the door is not opened or the alcohol is not sold.

The first type of behaviour is inherent to people who have maintained the connection with traditions. One of the important communicative rules that should be followed during the process of mutual transmission of the present or object of exchange within Chukchi and Eskimo cultures is verbal and nonverbal veiling of the process. This explains the difficulty in the formulations explaining the aim of the buyer after arrival, as was mentioned by all traders with whom I talked. Among Chukchis it is not acceptable to discuss a bargain, the etiquette does not allow one to express one's wishes openly. It is expected that the trader himself is able to understand the buyer's needs.

For the second type of behaviour I would like to suggest two explanations, grounded on the cultural peculiarities of Chukotka. The buyer's loud behaviour can be considered a deviation from native etiquette, appearing to be a reaction to 'Russian' activity. Rumbling and noisiness when arriving at someone else's home contradict the communicative traditions of the native inhabitants of Chukotka. Traditionally the arrival of a guest presupposes moderate behaviour. Any breach of the traditional etiquette during alcohol purchase is a cognitive attempt to become 'Russian' for the time of the bargain.

A buyer's behaviour when purchasing alcohol can be compared to the behaviour of a hungry child who goes to his parents. The child does not know the norms of behaviour, he or she demands, shows need, begs, and if he or she is not given what is wanted, becomes hysterical, shouts and cries. The trader or 'parent' can scold, objurgate or even beat the buyer as the buyer's behaviour is considered to be acceptable. The interaction between alcohol trader and buyer in this case can be characterised as the relationship between parent and child.

Paternalism towards Chukchis and Eskimos was inherent to the producers of homedistilled vodka, as is common to Russian newcomers in Chukotka. Projection of family metaphors to other social relations and situations, including trade, are inherent to native inhabitants. That is why the roles of trader (parent) and buyer (child) can be considered designations of the alcohol trading culture of settlements in Chukotka.

The group of temperance activists consists of a native inhabitant elite. They are people of mixed ethnic background who have education and work to save traditional culture and revive national traditions. In the economic sense, temperance activists work with the aim of negating the bargain - they interact with buyers, persuading them not to buy alcohol, and also interact with traders persuading them not to sell alcohol. As a result, temperance activists are situated between buyers and traders both economically as well as ethnically.

The movement against producers of home-distilled vodka is a confrontation between native intellectuals and 'Russians' - newcomers, strangers, who occupy jobs and have an influence on culture. This is not only a fight against alcoholism but also a hidden fight against an alien impact on a native culture.

Anastasiya Yarzutkina (Chukotka Branch of North-Eastern Federal University in Anadyr, Russian Federation) 